\title{
Public Security Practice and Countermeasures for Food Safety Protection*
}

\author{
Qin Wei \\ Department of Public Security Management \\ Hubei University of Police \\ Wuhan, China 430034
}

\begin{abstract}
Food is the paramount necessity of the people". The food and drug safety issue is related to the health and life of the people. At present, China has established an administrative regulation system with the "Drug Administration Law" as its core. The key is how to implement the food safety supervision system. Starting from the actual setting of the new police work in public security work, this paper focuses on the hot and difficult issues of "food and drug safety" in the reform and development of public security education. It advocates being good at using the rule of law and the rule of law, focuses on solving the problems of relevant laws and the problems in administrative law enforcement and criminal justice, and forms an overall synergy against drugrelated crimes.
\end{abstract}

Keywords-food safety; public security practice;
countermeasures

\section{INTRODUCTION}

In the past 20 years, developed countries have significantly reduced the administrative staff of the food and drug regulatory authorities, but at the same time increased the technical and law-enforcement personnel, trying to achieve refined and flat management. For example, the US Food and Drug Administration employed thousands of doctors in medicine, chemistry, and food engineering as technical support. It also attaches great importance to the training of food and drug safety police professionals, emphasizing an applied and professional training model. At the same time, tens of thousands of law enforcement police in the western developed countries have patrolled the front line of enterprise production. They are dressed in unified uniforms and even equipped with guns. Although China's food and drug safety has achieved remarkable results during the "Twelfth Five-Year Plan" period, the basic characteristics of national food and drug safety risks and contradictions have not changed fundamentally. At present, there are still some problems to be solved in the aspects of food and drug safety supervision system and mechanism, laws and regulations, combat prevention, policy standards, monitoring and evaluation, inspection and testing, talent team and technical equipment. In the case of heavy tasks, the public

*Fund Project: The Scientific Research Project of Hubei Provincial Department of Education in 2018 - Public Security Practice and Countermeasures for Food Safety Protection Against the Background of NTS (Project No.: B2018229). security organs have to come up with a considerable amount of energy to combat these new types of crimes, such as food and medicine, but this work is very professional and the combat power is very insufficient.

\section{CURRENT Public SECURITY Practice OF COMBATING FOOD AND DRUG SAFETY CRIMES}

The technical level and law enforcement capacity of the Chinese food and drug supervision department are still far from sufficient, and the number of relevant personnel and administrative personnel appears to be "upside down". In 2011, the national food and drug supervision system had 53,000 administrative personnel, but the technical support team had only 30,000 people. Among the above-mentioned personnel, only 15,000 were professional inspectors. Although the local food and drug supervision departments have set up inspection teams to investigate and deal with illegal cases, there is a widespread phenomenon of "taking penalty as punishment" in the process of law enforcement, that is, using administrative punishment to replace criminal judicial responsibility, so that it is difficult to transfer the case to the judicial organs, which also leads to a reduction in the illegal cost of food and drug manufacturing and holiday sales. Therefore, the crime against food safety was put on the government's agenda, and the public security organs were at the top of the list to combat food and drug safety crime activities.

Since 2013, a professional law enforcement team covering the whole country and cracking down on illegal activities in food and medicine has been established from the central government to the local government — "Food Medicine (Safety) Police". The establishment of this new type of police embodies the requirements of the public security organs to actively adapt to the modernization of the national governance system and governance capacity, closely peg the food and drug crimes that affect the people's livelihood, and firmly establish the legislative thinking. It also further strengthens the coordination and cooperation between the criminal justice department and the administrative law enforcement department, comprehensively enhances the ability to strike, focuses on promoting source governance, provides strong criminal protection for the "security on the tongue" of the people, and creates a strong social atmosphere for severely punishing and 
preventing drug-related crimes according to law. Since 2014 , various professional law enforcement teams in the fight against illegal food and drug crimes have been set up throughout the country — "Food Medicine (Safety) Police." Taking Wuhan as an example, the Office of the Food and Drug Law Enforcement Corps Liaison Office of the Food and Drug Crime Investigation Detachment of the Wuhan Municipal Public Security Bureau was established in April 2014. The establishment of this new type of police embodies the requirements of the public security organs to actively adapt to the promotion of the national governance system and capacity modernization. This requires China to further strengthen the coordination between the criminal justice department and the administrative law enforcement departments, and provide powerful criminal protection for the people's "security of every bite".

In May 2019, the Ministry of Public Security had established the Food and Drug Crime Investigation Bureau. Director Lu Wuqin said that he would actively work with relevant departments to maintain a high-pressure situation in crimes of food and drug, intellectual property rights, ecological environment, forest resources, bio-safety, and the production and sale of counterfeit and inferior commodities, and efforts will be made to make the sky bluer, water greener, food and medicine safer, and people's lives more reassuring, and to earnestly safeguard the seriousness of laws and regulations. According to the "2018 Annual Report on Drug Supervision and Statistics" promulgated by the State Food and Drug Administration on May 9, 2019, in 2018, the regulatory agencies at all levels investigated and handled 98,000 drug cases, with a value of 2.74 billion yuan and a fine of 7.66 billion yuan. The illegal proceeds were confiscated 2 billion yuan, 1037 unlicensed businesses were banned, 148 counterfeit and fake dens were destroyed, 1093 were suspended, 197 were revoked, and 2,000 were transferred to the judiciary.

\section{DifFICUltiES IN COMBATING FOOD AND DRUG SAFETY DELINQUENCIES}

\section{A. The Industrial Structure Is Scattered and the Criminal Means Are Increasingly Hidden}

Food and drug, especially food production and operation enterprises, have lower barriers to entry, SMEs account for the vast majority, and production and operation conditions are poor. Small, scattered and chaotic phenomena are common. With the development of the food industry, the variety of food additives is increasing; the production process and packaging materials are constantly innovating; and the regional food industry and new food industry such as food specialty townships (villages) are constantly emerging, which has raised new issues for food supervision. In recent years, with the continuous deepening of the special investigation and punishment work, the anti-investigation awareness of criminals involved in the food and drug field has been continuously enhanced. In order to evade the supervision and combat, when selecting the location of the crime, the criminal gangs often chose to set up counterfeit dens in the remote sections of the suburbs and in the abandoned factories. When selecting the perpetrators, most of them choose blood relatives, people-in-laws, fellows to form criminal gangs and offensive and defensive alliances, and it is difficult for outsiders to join in and master the internal situation. In the time of counterfeiting, they usually adopt the mode of evening processing and early morning delivery to increase concealment. In the food field, there are new methods of criminal offenses and crimes, and the scope of the counterfeiting and the "crafts" are taught among criminal gangs. The speed of the spread of criminal acts is accelerating.

\section{B. The Law Enforcement Guarantee Is Lagging Behind, Affecting the Impact of the Restriction and Combat}

The revision speed of criminal law and related judicial interpretations lags behind the development of food and drug safety issues. The existing national food safety standards are few, the standards are low, and they are seriously lagging behind. More than 25\% were formulated 10 years ago, and some have not been revised for 20 years. Many of the newly introduced standards are recommended standards and there is no legal force. The detection technology lags behind, especially lacking scientific and effective detection methods for illegal use of additives and abuse of food additives. It is difficult to detect the illegally added substances, and the detection and detection ability of harmful components such as waste oil is weaker, and it becomes a bottleneck in handling such cases.

\section{The Requirements for Case Investigation Are High, and the Actual Operation Is Difficult}

Food and drug safety crimes, especially food crime cases, often involve a large number of food raw materials, semifinished products and finished products to be seized. These items are not only bulky, but also prone to decay and deterioration. They require high storage and storage, and many require refrigeration. In the case handling, according to the requirements of property management involved, not only it is difficult to deal with, but also the destruction after the trial is difficult. In addition, such cases have many evidenceacquisition links, high standards, strict sampling control, and need to be sent to provincial-level testing institutions, resulting in high cost of case testing.

\section{The Basis of the Combat and Defense Work Is Weak, and the Funding Guarantee Is Obviously Insufficient}

Defending and combating food and drug crimes is faced with a large number of food production and processing enterprises, small workshops and markets covered a large scale of area. At present, Wuxi is relatively in place at the city first-level equipment of institutional setup and specialized strengths. The public security organs have also set up the food and drug safety crime investigation agency. However, there has not been a special combat team at the county and district levels. Most of the investigation tasks for food and drug crime cases are undertaken by the public security department, and the personnel strength and work energy are not guaranteed. In particular, the on-site quickchecking equipment, inspection and identification equipment 
and on-site inspection special vehicles necessary for public security organs to combat food and drug safety crimes are not configured, and they are basically in a state of starting from scratch and unarmed.

\section{MAIN COUNTERMEASURES}

\section{A. Implementing the Food and Drug Safety Responsibility System}

In accordance with the overall requirements of "unified institutions, shifting the focus, standardizing law enforcement, sound mechanisms, and fairness and efficiency", it will be necessary to establish and improve the regulatory agencies with corresponding correspondence, powers and responsibilities, and uniform standards. It will also be necessary to establish food and drug supervision and administration institutions at the provincial, municipal and county levels as the government's work department at the same level as well as highlighting the construction of grassroots supervision capacity, establishing food and drug supervision agencies in towns and villages, and uniformly performing the duties of food and drug supervision and administration in the administrative region. According to the requirements of the food and drug safety responsibility system of "The party and government having the overall responsibility, the supervision departments performing their duties, the relevant departments are responsible respectively, the grassroots grid supervising, and the production and management personnel bearing the main responsibility", forming a scientific and rigorous division of responsibility for food and drug safety, and implementing the assessment and evaluation and fault investigation mechanism.

\section{B. Improving the Food and Drug Regulations and Standard System}

Focusing on scientific supervision, legal supervision, effective supervision, and strict supervision, it will be important to solidly promote the construction of food and drug safety regulations and standards. It will also be important to establish the most rigorous supervision system covering the whole process and the regulatory rules with universal shocking effect, establish and improve the abnormal catalogue of food and drug management, improve the systems of production place exit and market admittance of edible agricultural products, the voluntary recall of defective products, mandatory withdrawal and destruction, etc., and formulate a ceiling penalty list and procedures. At the same time, it will be necessary to explore and improve the management systems of the first responsibility of food and drug producers, compulsory insurance, civil compensation, and quality and safety authorized persons.

\section{Building a Food and Drug Safety Risk Management System}

It will be of great significance to further deepen the construction of food and drug risk management system, achieve the "early discovery, early judgment, early warning, early disposal" of risks and hidden dangers, and strengthen risk monitoring. It will also be very important to comprehensively strengthen the monitoring of foodborne diseases, food contaminants and toxic substances in food The foodborne disease surveillance reporting system covers all types of medical service institutions at all levels. There are 167 food-borne disease surveillance sites in the province, and the monitoring network of food pollutants and harmful factors covers all county-level administrative regions and extends to rural areas. It will be necessary to continuously improve adverse drug reactions, medical device adverse events, cosmetic adverse reactions, drug abuse monitoring mechanisms, improve key monitoring of adverse reactions, and actively monitor systems and feedback, communication, disposal and accountability mechanisms for medical device adverse events.

\section{Creating a Food and Drug Safety Emergency Response System}

With the improvement of capacity as the core and the support of information construction, the food and drug safety emergency management work will be comprehensively strengthened, and an emergency response system with strong command, responsiveness, coordination and order, and high efficiency will be expedited.

1) Improving the emergency management mechanism: In accordance with the requirements of clear responsibilities, coordinated and efficient operation, it will be necessary to establish and improve mechanisms for monitoring and early warning, emergency support, social mobilization and summary assessment. It will also be necessary to promote cross-regional and inter-departmental emergency coordination, information and other mechanisms. Moreover, preparing food and drug safety emergency plans, coordinating and arranging various types of emergency plan revision, drill and training, and improving the emergency plan system will also be very important. It will be of great significance to improve the rules and regulations for the prevention of emergencies and accidents, and improve the standardization and institutionalization of emergency management, as well as supervising and guiding food and drug producers and operators to improve the construction of emergency management mechanisms, and enhancing the ability of production and management personnel to investigate and control hidden dangers and respond to emergencies. It will also be very important to select some municipal and state bureaus to carry out food and drug safety emergency management pilots, sum up experience, and promote the overall system emergency management of the province.

2) Improving monitoring and early warning capabilities. Strengthening the construction of food and drug safety public opinion monitoring system, improving the informationization and intelligence level of public opinion monitoring, and realizing 24-hour continuous monitoring of public opinion information to realize early detection, early report and early warning of emergency information will be significant. It will be made great efforts to stablish and 
improve inter-regional and multi-sectoral information sharing mechanisms, and improve the ability to obtain relevant information and organize verification and processing from multiple channels, multiple channels, such as supervision and sampling, risk monitoring, adverse reaction monitoring, complaints and reports.

3) Strengthening emergency response: What needs to do is to establish and improve food and drug safety emergency command and decision system, early warning information reporting system, response disposal system, information release system, and results evaluation system, and improve emergency command and decision making and mobilize organizational coordination efficiency. It will also be necessary to strengthen the construction of emergency teams, establish a food and drug supervision team as the basic strength. Taking the technical support team such as inspection, evaluation and verification as the professional force, supplemented by the assistants, informants, volunteers and industry associations, the arrangement in construction of emergency response teams is also needed to be improved. What is also important is to establish a library of food and drug emergency management experts covering all areas of the system, strengthen and standardize the management of the expert database, and give full play to the role of the expert group in emergency response. At present, some illegal crimes in the field of food and drug are still prominent. The problem of insufficient understanding and weak law enforcement in some places still exists. There are still some problems that need to be solved in the process of law enforcement convergence. The standards are different and different cases are also different in judgement.

\section{CONCLUSION}

Public security organs should increase investment in food and drug investigations, and further improve the means of transportation, inspection and testing equipment, evidenceacquisition tools and information equipment used in law enforcement. It is emphasized that it is necessary to strengthen the coordination between administrative law enforcement and criminal justice, further standardize and refine the two-way transfer system of cases and clues, enhance the administrative agency's awareness of criminal prosecution of criminals and case evidence preservation, and improve the efficiency of administrative law enforcement and criminal justice convergence and the transfer of case clues. All law enforcement agencies should jointly study the characteristics and development trends of food and drug crimes in the region on a regular basis, and negotiate the striking and precautionary countermeasures. It is also necessary to strengthen cooperation with administrative law enforcement agencies such as drug supervision, industry and commerce, health, agriculture, animal husbandry, and postal services, establish an information exchange platform to achieve information exchange and sharing, and timely obtain information such as basic information, appraisal conclusions, and punishment contents of administrative law enforcement agencies, as well as acquiring the case clues in multi-level, all-round to provide information support for precision strikes.

\section{REFERENCES}

[1] Ma Songiian, Pan Zhaodong, Discussion on the Strategy of Criminal Law of China's Food and Drug Crime [J]. Journal of Henan Public Security Academy, 2018 (8). (in Chinese)

[2] Chief observer, Hubei Setting up a "Food and Drug Police" Agency Responsible for Food and Drug Investigation Cases [J]. Food Safety Guide, 2015 (9). (in Chinese)

[3] Li Chunlei, Retrospect and Prospect of China's Food and Drug Crime Prevention [J]. Journal of Chinese People's Public Security University: Social Sciences Edition, 2015 (8). (in Chinese)

[4] Luo Binfei, Food and Drug Safety's Social Governance: the Restric Elements and Strategies [J]. Enterprise Economy, 2015 (5). (in Chinese)

[5] Zhang Qi, The Problems and Strategies to Establish "Food and Drug Police" in China [J]. Journal of Railway Police, 2014 (12). (in Chinese) 